\title{
Metrics and Benefits Analysis and Challenges for Smart Grid Field Projects
}

\author{
S. J. Bossart, Team Lead, U.S. Department of Energy, and J. E. Bean, Project Manager, U.S. \\ Department of Energy
}

\begin{abstract}
This paper describes approaches to determine metrics, costs, and benefits from Smart Grid field projects including the 140 Smart Grid Investment Grants and Smart Grid Demonstration Projects funded by the U.S. Department of Energy (DOE) through the American Recovery and Reinvestment Act. The paper describes DOE's metrics and benefits framework that links Smart Grid technologies with their applications and the benefits that result from those applications. Benefits are derived by comparison of grid performance before and after installation and operation of Smart Grid components. These benefits are accrued to utilities/ratepayers, consumers, and society. There are significant challenges in attempting to collect field information and convert the information to metrics, costs, and benefits. For example, determining the monetary value of performance benefits such as reduced environmental emissions, reduced outages, and reduced peak load requires assumptions based on experience and must be rooted in solid technical and financial bases.
\end{abstract}

Index Terms-analysis, grid assets, grid modernization, metrics and benefits, Smart Grid, Smart Grid functions, Smart Grid Demonstration Program, Smart Grid Investment Grant

\section{INTRODUCTION}

$\mathrm{T}$ hrough the American Recovery and Reinvestment Act, the U.S. Department of Energy (DOE) and other funding has initiated 99 Smart Grid Investment Grants and 41 Smart Grid Demonstration Projects. Collectively, these projects are valued at about $\$ 10$ billion and constitute the single large investment and deployment of Smart Grid technologies and systems in our nation's history. In addition, the Electric Power Research Institute has launched a similar Smart Grid Demonstration Program which includes 11 demonstration projects. The deployment of these Smart Grid projects represents the first significant opportunity to collect field information to determine the benefits of Smart Grid, compare the benefits to the costs, and build future business cases. Information from these projects is expected to better inform investors and decision makers on future deployments of Smart Grid.

Previous paper studies have shown a benefit-to-cost ratio ranging from $4: 1$ to $6: 1[3,4,5]$. An intent of the collecting data from Smart Grid projects is to confirm that the benefits of

This work is supported by the American Recovery and Reinvestment Act (ARRA) funding, and overseen by the U.S. Department of Energy.

S.J. Bossart (email: steven.bossart@netl.doe.gov) and J.E. Bean (email: Jacquelyn.bean@netl.doe.gov) are with the Department of Energy's National Energy Technology Laboratory.
Smart Grid greatly outweigh its costs.

This paper describes analytical approaches being used to determine the performance metrics, benefits, and cost of Smart Grid projects along with several of the challenges.

\section{SMART GRID METRICS AND BENEFITS}

\section{A. Metrics and Benefits Framework}

DOE's analytical framework will link Smart Grid technologies deployed or leveraged under DOE's Smart Grid projects to up to 25 benefits accrued by three stakeholder groups (i.e., utility/ratepayer, consumer, and society). The framework asks several key questions (Fig. 1):

- What is the technology? (i.e., "Assets")

- What does the technology do? (i.e., "Functions" or "Storage Applications" for energy storage technologies)

- How does it do that? (i.e., "Mechanisms (Impacts)")

- What goodness results? (i.e., "Benefits")

- What is the goodness worth? (i.e., "Monetary Value")

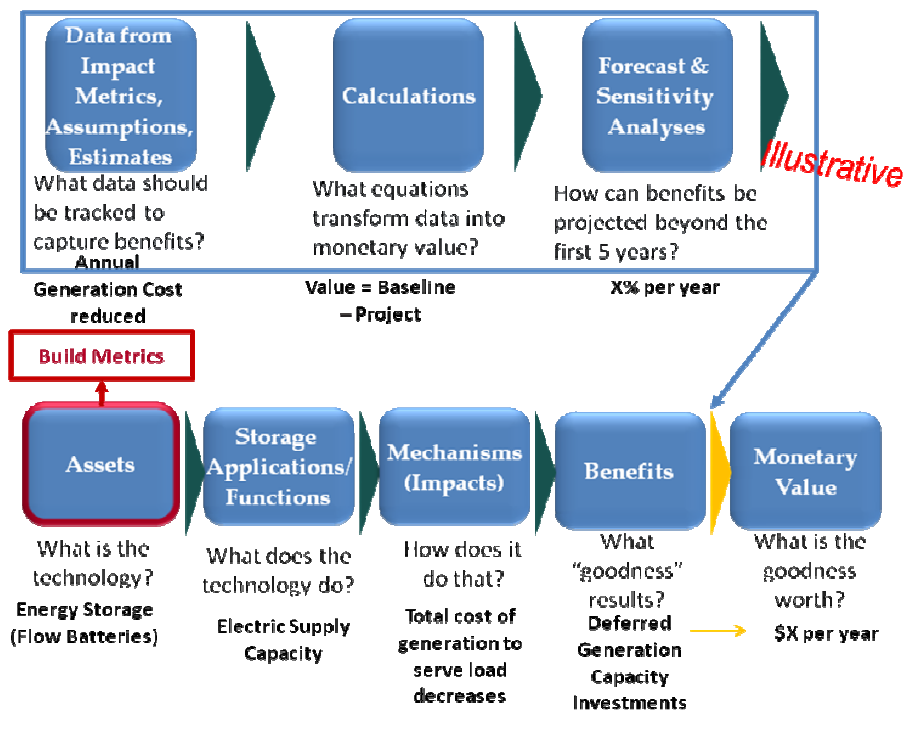

Fig. 1. Smart Grid Metrics and Benefits Analytical Framework

DOE is attempting to answer these questions by defining and tracking the Smart Grid Program's assets and their impact on the grid, consumers, and society. DOE is tracking "Assets" via build metrics reporting by projects, which includes monetary investments (i.e., installed equipment costs), the creation and retention of jobs, and Smart Grid technologies 
and pricing programs (grouped under the categories of Advanced Metering Infrastructure, Customer Systems, Pricing Programs, Distributed Energy Resources, Distribution, and Transmission).

DOE is tracking "Mechanisms (Impacts)" via impact metrics reporting by projects, which include metrics that measure how and to what extent the project is affecting grid operations and performance, or how it is enabling customer programs. For example, a project might show a reduction in truck rolls by implementing automated feeder switching. Another project might show a drop in peak demand from a real-time pricing program.

Projects will report both baseline and project and systemlevel build and impact metrics. Baseline should reflect the parameter values without the DOE Smart Grid Program project, analogous to "business as usual" in a business case analysis. For example, baseline could be established using historical performance data on the feeder(s) or data collected on the feeder(s) during the project prior to the operation of the Smart Grid technologies. Project-level metrics pertain to the project-funded technologies and the impact of those technologies on operations in the demonstration area(s). System-level metrics pertain to technologies that already exist or are being installed in a project separate from the DOE Smart Grid Program, or impacts from project-funded technologies that extend beyond the demonstration area(s) into the broader utility system. For example, a project demonstrates power flow control by installing FACTS devices funded by the DOE Smart Grid Program and using existing phase angle regulating transformers. The project should capture FACTS devices under project-level and phase angle regulating transformers under system-level.

Furthermore, for energy storage-specific projects, DOE will be tracking energy storage applications, which include specific technical considerations such as minimum discharge duration, and the following system performance information:

- System Characteristics-profile of the system such as footprint and energy density

- Data Measurements-storage system measurements and recordings such as battery system state of charge and import/export energy signals

- System Performance Parameters - technical, economic, and environmental health \& safety (EHS) performance characteristics that will be measured or calculated during the project such as round-trip efficiency and operating temperature

- Projected Performance Parameters-performance characteristics that will require extrapolating or forecasting based on data collected during the demonstration such as long-term capacity degradation and cycle life

DOE has identified and mapped key Smart Grid "Assets" to 13 "Functions" that may be enabled by Smart Grid (Fig. 2). The "Functions" and three energy resources have then been mapped to 25 Economic, Reliability, Environmental, and Security "Benefits" (Fig. 3).
In order to quantify these benefits (i.e., "Monetary Value"), DOE has supported the development of a Smart Grid Computational Tool. This tool identifies, organizes, and processes the inputs (e.g., "Assets", "Functions", "Mechanisms (Impacts)", and "Benefits") required to analyze a project. For example, the "Function" of Enhanced Fault Protection can realize a "Benefit" of Reduced Equipment Failures through the following calculation: $(\$)$ = Capital Replacement of Failed Equipment $(\$) *$ Portion of Failed Equipment Caused by Fault Current or Overloaded Equipment (\%). The tool can also perform Net Present Value and sensitivity analyses [5,6].

\section{B. Categories of Benefits}

It is important to recognize that not all stakeholders will benefit from the Smart Grid equally and DOE is making efforts to use the Smart Grid field information to delineate the benefits to utilities/ratepayers, consumers, and society. Utilities will benefit from Smart Grid through improved operations including more accurate and automated metering and billing, better outage management, reduced electrical losses, better asset utilization, improved maintenance, and improved planning processes. Consumers will benefit through more reliable service, reduced businesses losses, potential bill savings, reduced transportation costs through electric vehicles, and ability to access real-time information with options to control their electrical use. Society will benefit from the Smart Grid by reducing import of crude oil by transportation electrification, improving the security of electricity delivery, and reducing environmental emissions by enabling more renewable energy resources. Smart Grid represents an opportunity to create new domestic jobs for design, construction, operation and maintenance of Smart Grid; for manufacturing Smart Grid components, and for providing Smart Grid services. Smart Grid is a vital component that enables U.S. companies and economy to compete in the global marketplace.

\section{Challenges}

Metrics, cost and benefits analysis of Smart Grid field projects has some major challenges. These challenges include:

- Enabling a fair comparison of baseline performance and Smart Grid performance

- Collecting proper data at appropriate frequency and location

- Determining societal benefits

- Monetizing benefits

- Extrapolating results from a few circuits to larger control area

- Interpreting Smart Grid response to electrical disturbance

- Recognizing regional differences for electric service provider and consumer

- Using appropriate assumptions and calculation methods

More discussion is warranted for some of these challenges. For example, to enable a fair comparison of baseline and the Smart Grid system, it may be necessary make adjustments to account for differences in weather conditions, abnormal system disturbances, maintenance, load and other factors 
between the baseline period and the Smart Grid demonstration/deployment period.

Appropriate field data needs to be collected in the proper frequency and location as it provides the raw information that must be used in calculations to determine performance metrics and benefits. Since these Smart Grid projects represent the first large opportunity to collect field data, we must be prepared to adjust our data collection requirements as we learn more about operation of the Smart Grid system.

Among the societal benefits of Smart Grid are cleaner air, improved safety, reduced dependency on foreign oil, and reduced costs of goods and services. These benefits are real, but difficult to calculate and monetize based on field data from Smart Grid projects. However, it is important to account for these improvements made possible by Smart Grid in the business case and decision making for Smart Grid. We will be exploring the underlying assumptions and calculation methods for determining societal benefits to assure that they are as credible as possible.

During periods of disturbances on the electric grid (e.g., outages or power quality issues), it may be important to adjust the data collection approach by changing the type, frequency, and location of data collected during transient conditions. One of the benefits of Smart Grid is "self-healing" by being able to anticipate and respond to system disturbances before they become a major problem. One of the challenges of the "self healing" feature of Smart Grid is to demonstrate how Smart Grid was able to prevent the occurrence of a major event such as outages, equipment damage, and power quality issues and determine the value associated with preventing those events.

\section{Observations}

In addition to quantifying and monetizing performance of the Smart Grid and impacts to consumers and society, it is important to record observations and reactions to Smart Grid from utility workers (e.g., planners, designers, operators, and maintenance crews), consumers, regulatory commissioners, and other stakeholders. There is a need to understand how Smart Grid has improved or worsened the ability of utility workers to perform their jobs and how Smart Grid has impacted the convenience, comfort, and electricity bills for consumers. In fact, several of the Smart Grid Investment Grant (SGIG) projects have volunteered to participate in consumer behavior studies on dynamic pricing to better understand how Smart Grid education and dynamic pricing affect consumer behavior. Often, these observations will reveal unintended consequences of Smart Grid - both good and bad.

\section{E. Performance Feedback}

The DOE has initiated a Performance Feedback Program to capture and share case studies, best practices, and lessons learned from Smart Grid field projects. It is vital that organizations moving forward with Smart Grid learn from theirs and others experiences and apply those experiences to their implementation approaches. The Performance Feedback Program is a focused effort to share those experiences so that mistakes are not repeated and state-of-the-art for Smart Grid is continually advanced. The Performance Feedback Program will help keep implementation costs down, provide input for codes and standards development, create processes for corrective actions, and enable organizations to benchmark their Smart Grid projects with best-in-class for various Smart Grid applications. 


\section{APPENDIX}

\begin{tabular}{|c|c|c|c|c|c|c|c|c|c|c|c|c|c|}
\hline \multirow[b]{2}{*}{ Smart Grid Assets } & \multicolumn{13}{|c|}{ Functions } \\
\hline & 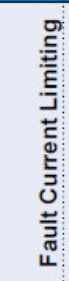 & 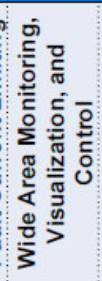 & 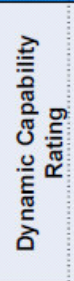 & 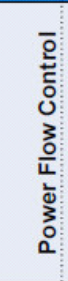 & 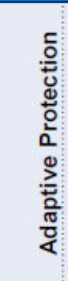 & 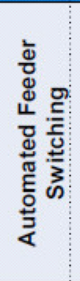 & 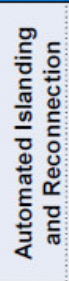 & 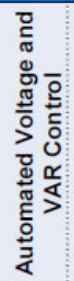 & 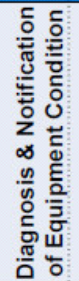 & 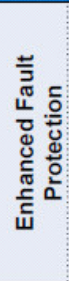 & 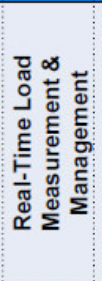 & 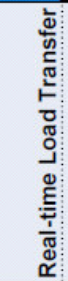 & 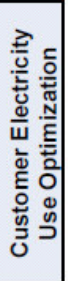 \\
\hline Advanced Interrupting Switch & & & & & & & & & & - & & & \\
\hline AMI/Smart Meters & & & & & & & & - & & & • & & - \\
\hline Controllable/Regulating Inverter & & & & & & & - & - & & & & & \\
\hline Customer EMS/Display/Portal & & & & & & & & . & & & & & - \\
\hline Distribution Automation & & & & & • & - & - & - & & & & - & \\
\hline Distribution Management System & & & • & & - & - & - & - & & & - & - & \\
\hline Enhanced Fault Detection Technology & & & & & & & & & & - & & & \\
\hline Equipment Health Sensor & & & • & & & & & & • & & & & \\
\hline FACTS Device & & & & - & & & & & & & & & \\
\hline Fault Current Limiter & - & & & & & & & & & & & & \\
\hline Loading Monitor & & & - & & & & & & • & & & - & \\
\hline Microgrid Controller & & & & & & & - & & & & & & \\
\hline Phase Angle Regulating Transformer & & & & - & & & & & & & & & \\
\hline Phasor Measurement Technology & & - & - & - & - & & - & - & & - & & & \\
\hline Smart Appliances and Equipment (Customer) & & & & & & & & & & & & & - \\
\hline Software - Advanced Analysis/Visualization & & - & - & & & & & & & & & & \\
\hline Two-way Communications (high bandwidth) & & - & & & - & - & - & - & & & - & - & \\
\hline Vehicle to Grid Charging Station & & & & & & & & & & & & & - \\
\hline Vu (HTS) Cables & & & & • & & & & & & & & & \\
\hline
\end{tabular}

Fig. 2. Smart Grid Assets Mapped to Functions

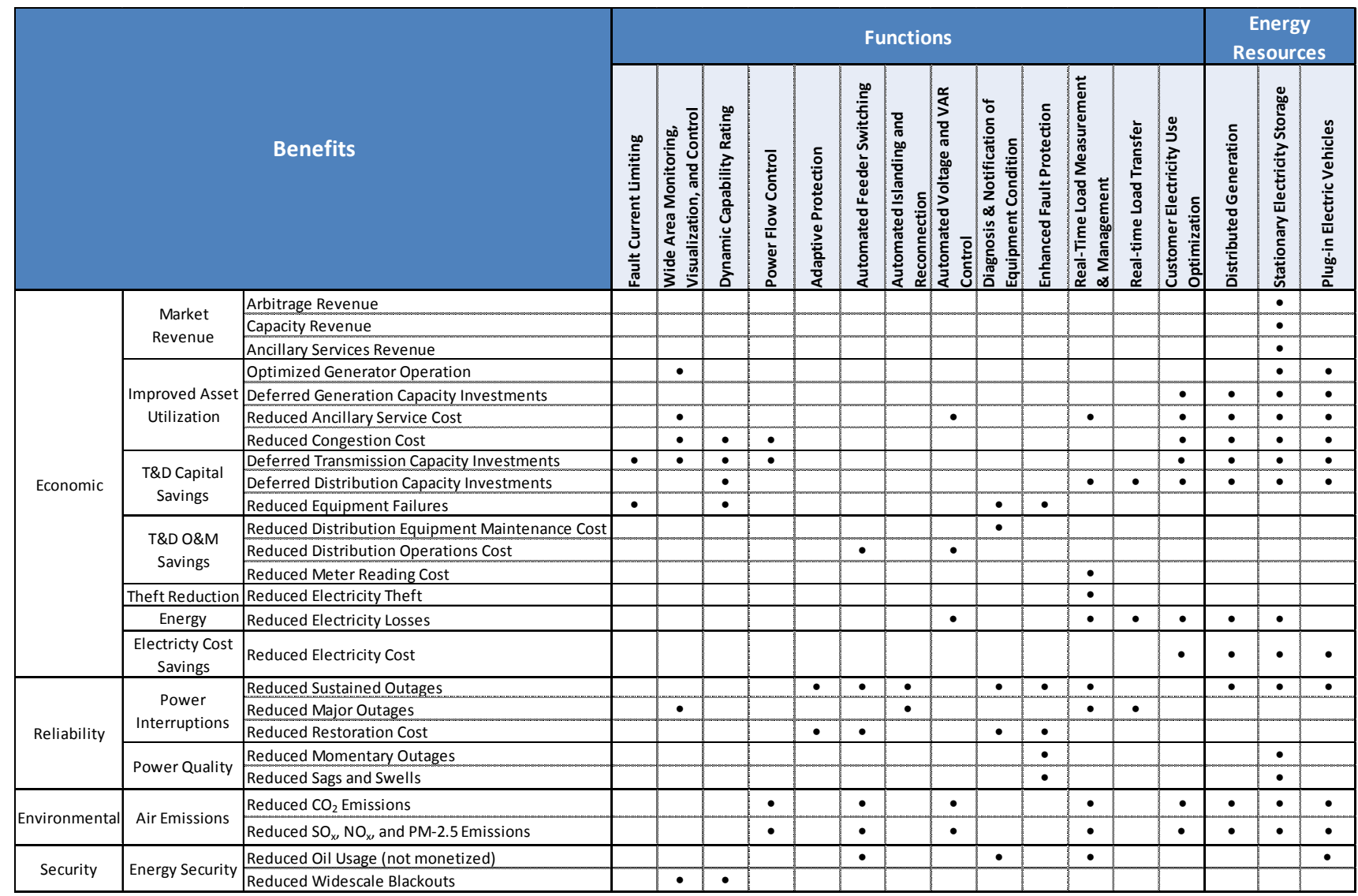

Fig. 3. Benefits Mapped to Functions and Energy Resources 


\section{ACKNOWLEDGMENT}

The authors gratefully acknowledge the contributions of Navigant Consulting, Inc. on behalf of the DOE.

\section{REFERENCES/BIBLIOGRAPHY}

[1] Federal Smart Grid website, http://www.smartgrid.gov/

[2] Smart Grid Information Clearinghouse, www.sgiclearinghouse.org

[3] West Virginia Smart Grid Implementation Plan, DOE/NETL2009/1386,August2009,

www.netl.doe.gov/smartgrid/referenceshelf/reports/WV\%20SGIP\%20Fi nal\%20Report\%20rev1.pdf

[4] San Diego Smart Grid Study Final Report www.sandiego.edu/epic/research_reports/documents/061017_SDSmart GridStudyFINAL.pdf

[5] Methodological Approach for Estimating the Benefits and Costs of Smart Grid Demonstration Projects, Product ID 1020342, http://my.epri.com/portal/server.pt?Abstract_id=000000000001020342

[6] Guidance documents for Smart Grid Investment Grants and Smart Grid Demonstration Projects, http://www.smartgrid.gov/teams

[7] Power Delivery System of the Future: A Preliminary Estimate of Costs and Benefits, EPRI Report, Product ID No. 1011001, http://my.epri.com/portal/server.pt?Abstract_id=000000000001011001

\section{BIOGRAPHIES}

Steven J. Bossart is employed by the U.S. Department of Energy at the National Energy Technology Laboratory (NETL). He has 26 years of project management and analytical experience at NETL. His areas of expertise include Smart Grid, homeland security, emergency response, nuclear decommissioning, environmental remediation, coal gasification, sulfur and particulate control, ash management, wastewater treatment, and National Environmental Policy Act. Previous employers include Liquid Carbon Corporation, Institute of Gas Technology, ARI Industries, and Mine Safety Appliances. He received a B.S. degree in Chemical Engineering from Pennsylvania State University.

Jacquelyn E. Bean is employed by the U.S. Department of Energy at the National Energy Technology Laboratory (NETL). She is currently a DOE Project Manager in the Smart Grid Investment Grant (SGIG) and Renewable and Distributed Systems Integration (RDSI) Programs, and oversees metrics and benefits reporting and data analysis for the RDSI and Smart Grid Demonstration Program (SGDP). Her focus areas include Smart Grid, renewable energy, power generation forecasting, energy storage, and energywater nexus. She previously worked in the Energy Practice at Navigant Consulting, and graduated from the Claremont Colleges. 